\title{
YÊU CÂU KỸ NĂNG MỀM CỦA LAO ĐỘNG TRONG THỜI KỲ HộI NHẬP
}

PGS.TS. Hà Nam Khánh Giao, Trưởng Khoa Đào tạo Sau Đại học

Trường Đại học Tài chính - Marketing, email: khanhgiaohn@yahoo.com, điện thoại: 0903306363

ThS. Nguyễn Thị Hồng Mơ, nhân viên công ty TNHH Best Buy Vietnam TÓM TẮT

Hội nhập sẽ mở ra nhiều cơ hội việc làm, dòng chảy lao động được tự do, nhiều yêu cầu cao hơn đối với người lao động, với tiêu chí tuyển dụng cao hơn đòi hỏi nguồn nhân lực ngoài kiến thức chuyên môn thì phải có kỹ năng mềm.

Tù Khóa: kỹ năng mềm, lao động, thòi kỳ hội nhập

\section{REQUIRING SOFT SKILLS FOR LABORS IN INTEGRATING PERIOD}

\begin{abstract}
Integrating to world economy will open many chances for labors, labor flows will be fluently, there will be a lot of demand for labors, and the employment criteria will be higher, so that it request the labor to have more softs skills, besides knowledge.
\end{abstract}

Keywords: soft skills, labor, integrating period

Giai đoạn hội nhập kinh tế và thị trường lao động, điều cạnh tranh lớn nhất chính là yếu tố con người. Do đó, các nhà tuyển dụng ngày nay đã thực tế lại càng thực tế hơn rất nhiều. Họ không chỉ muốn thu nhận người biết làm công việc chuyên môn, mà còn phải có khả năng sáng tạo, biết cách giải quyết các phát sinh trong công việc, phối hợp hiệu quả với đồng nghiệp, có tư duy tích cực và muốn thăng tiến cao hơn. Kỹ năng mềm được khẳng định là công cụ hữu hiệu nhất cho thành công trong nghề nghiệp của mỗi người.. 
Một cuộc khảo sát của Trung tâm Dự báo nhu cầu nhân lực và Thông tin thị trường lao động TP. Hồ Chí Minh đối với những người làm việc hiệu quả và thăng tiến nhanh cho thấy, chỉ có $25 \%$ là do những kiến thức chuyên môn, $75 \%$ còn lại được quyết định vởi những kỹ năng mềm họ được trang bị.

\section{Thực trạng}

Mặc dù giáo dục, đào tạo và phát triển nguồn nhân lực của Việt Nam đã đạt được một số thành tựu ban đầu, song vẫn còn rất nhiều hạn chế. Thực tế cho thấy Việt Nam có mức tăng trưởng thu nhập tương đối khá, nhưng nguồn lao động đang phải đối mặt với nhiều thách thức.

\section{Thiếu hụt kỹ năng trên thị trường lao động.}

Việt Nam có nguồn nhân lực dồi dào và trẻ, nhưng tỷ lệ của người có nghề và có trình độ chuyên môn trên số dân của cả nước rất thấp so với các nước trong khu vực; số lao động quản lý và kỹ thuật cao chiếm rất ít so với dân số cũng như so với quy mô nền kinh tế. Sự thiếu hụt các kỹ năng mềm đang là một trong những trở ngại chính đối với khả năng cạnh tranh của Việt Nam trong nền kinh tế hội nhập.

Nhân lực là yếu tố then chốt đối với sự phát triển của doanh nghiệp, do đó các doanh nghiệp rất chú trọng tới công tác tuyển dụng với mong muốn chọn lựa được ứng viên có năng lực. Nhưng thực tế cho thấy các doanh nghiệp không ngừng than phiền về chất lượng nhân viên của mình, đặc biệt là các doanh nghiệp có vốn đầu tư nước ngoài.

Nghiên cứu của CIEM về nhu cầu kỹ năng lao động cũng phát hiện một số vấn đề đáng quan tâm. Đặc biệt, kỹ năng của lao động đang trở nên ngày càng quan trọng để các doanh nghiệp tạo ra sự khác biệt và tăng khả năng cạnh tranh. Kiến thức chuyên môn của lao động là cốt lõi, nhưng cũng không thể thiếu được các kỹ năng mềm. Kết quả điều tra cho thấy doanh nghiệp chú trọng tới các kỹ năng khác nhau (những kỹ năng quan trọng nhất) khi tuyển dụng lao động vào vị trí nghề nghiệp khác nhau và coi đó là một trong những yêu cầu tuyển dụng quan trọng. Đối với vị trí tuyển dụng là nghề nghiệp kỹ năng cao (gồm cán bộ kỹ thuật và chuyên gia), doanh nghiệp coi trọng các kỹ thuật cụ thể liên quan đến công việc. 
Đối với vị trí tuyển dụng là cán bộ quản lý, doanh nghiệp đề cao kỹ năng lãnh đạo. Đối với nhóm nghề nghiệp gồm nhân viên văn phòng, lao động trong lĩnh vực dịch vụ và nhân viên bán hàng, doanh nghiệp nhấn mạnh tới kỹ năng giao tiếp. Đối với nhóm nghề nghiệp gồm lao động được đào tạo về nông, lâm, ngư nghiệp, thợ thủ công, lao động lắp đặt, vận hành máy móc và nhà xưởng, lao động nghề sơ cấp, doanh nghiệp coi trọng kỹ năng làm việc nhóm.

Một số tổ chức quốc tế đánh giá: $80 \%$ nhân viên văn phòng ở Việt Nam thiếu kỹ năng; tỷ lệ này ở lao động kỹ thuật, lao động phổ thông là $83 \%$ và $40 \%$. Tại Hội thảo Chính sách tiền lương trong bối cảnh kinh tế thị trường và hội nhập do Bộ Lao động - Thương binh và Xã hội phối hợp với ILO tổ chức tại Hà Nội tháng 11 năm 2014, bà Nicola Connolly, Chủ tịch Phòng Thương mại Châu Âu tại Việt Nam, phàn nàn lao động Việt Nam quá thiếu các kỹ năng mềm phục vụ công việc, hầu hết các doanh nghiệp Châu Âu phải đào tạo lại trước khi sử dụng.

Như vậy, có thể thấy các doanh nghiệp hiện nay đang gặp nhiều khó khăn trong việc tuyển dụng lao động mà nguyên nhân chủ yếu là do ứng viên thiếu các kỹ năng. Bằng cấp thể hiện trình độ chuyên môn của người lao động dường như không hoàn toàn quyết định hiệu quả tìm việc vì hiện nay nhiều doanh nghiệp ít chú ý tới bằng cấp và đang ngày càng chú trọng hơn vào các kỹ năng mềm khi tuyển dụng lao động. Bằng cấp chỉ là điều kiện cần thiết để ứng viên được phỏng vấn. Nhóm kỹ năng mà người lao động thường không đáp ứng bao gồm: ngoại ngũ̃, kỹ năng giao tiếp, kỹ năng làm việc nhóm, khả năng sáng tạo và kỹ năng giải quyết vấn đề,... Nhiều doanh nghiệp cũng phản ánh rằng các kỹ năng mà lao động đã được đào tạo bị lệch so với các kỹ năng mà doanh nghiệp cần. Một số nhà tuyển dụng than phiền rằng nhân viên trẻ có kỹ năng mềm rất yếu, không đáp ứng được công việc dù có bằng cấp tốt. Các doanh nghiệp nhìn chung đã ý thức được vấn đề này và hầu hết các doanh nghiệp đều phải đào tạo lại cho người lao động mới tuyển dụng

Các doanh nghiệp cũng phản ánh rằng lao động được đào tạo ở Việt Nam chưa được trang bị kỹ năng sống, chưa ý thức được quyền và nghĩa vụ, thiếu ý thức, tác phong, tính kỷ luật trong lao động. Phần lớn các doanh nghiệp cho rằng hệ thống đào tạo nghề và kỹ thuật 
nói riêng cũng như hệ thống giáo dục nói chung ở Việt Nam chưa đáp ứng được yêu cầu về kỹ năng mà doanh nghiệp cần.

\section{Thiếu hụt kỹ năng mềm đối với học sinh, sinh viên}

Thiếu hụt kỹ năng là một trong những điểm yếu của lao động khi Việt Nam tham gia quá trình hội nhập. Do đó, vấn đề đặt ra đối với học sinh, sinh viên hiện nay là làm thế nào để được các doanh nghiệp tuyển dụng theo nghề đã được đào tạo và làm việc có hiệu quả, có khả năng phát triển nghề nghiệp. Muốn vậy, học sinh, sinh viên phải được trang bị và nâng cao cả kỹ năng cứng (trong đó có đào tạo nghề) và kỹ năng mềm. Rõ ràng, đào tạo nghề có vai trò quan trọng đối với việc nâng cao chất lượng nguồn nhân lực và qua đó tạo ra sự phát triển cho tương lai. Tuy vậy, hiện nay kỹ năng nghề và nhất là kỹ năng mềm chưa thật sự được ngành giáo dục chú trọng quan tâm, đặc biệt trong giáo dục phổ thông (Một số tổ chức quốc tế đánh giá có tới $40 \%$ lao động phổ thông ở Việt Nam thiết kỹ năng mềm). Người lao động chủ yếu có được các kỹ năng mềm thông qua tích lũy kinh nghiệm.

Theo số liệu của Viện Nghiên cứu Giáo dục Việt Nam, hiện nay có đến $83 \%$ sinh viên tốt nghiệp ra trường bị đánh giá là thiếu kỹ năng mềm, $37 \%$ sinh viên không tìm được việc làm phù hợp do kỹ năng yếu. Còn theo điều tra của Bộ Lao động - TB\&XH, trong tổng số các sinh viên tốt nghiệp hàng năm, hơn 13\% phải được đào tạo lại hoặc bổ sung kỹ năng, gần $40 \%$ phải được kèm cặp lại tại nơi làm việc và $41 \%$ cần thời gian làm quen với công việc qua một thời gian nhất định mới có thể thích ứng.

\section{Giải pháp}

\section{Đối với học sinh, sinh viên}

Trong giáo dục phổ thông hiện nay, mặc dù đã có nhiều cải cách về chương trình giáo dục như hạn chế tính lý thuyết, tăng cường thực hành..., song chương trình vẫn được xây dựng theo hướng tiếp cận nội dung, thiên về trang bị kiến thức khoa học, chưa chú trọng tới các kỹ năng cần thiết khác như kỹ năng nghề và kỹ năng mềm cho học sinh (thiếu định hướng thực tiễn nghề nghiệp, thiếu và yếu trong phát triển kỹ năng quan hệ qua lại giữa các cá nhân...). 
Do đó, bài viết đề xuất một số giải pháp đổi mới chương trình giáo dục phổ thông nhằm trang bị tốt hơn các kỹ năng cho học sinh, chuẩn bị những tiền đề hướng nghiệp tốt nhất cho học sinh sau khi tốt nghiệp để dễ dàng tiếp cận thị trường lao động. Trước mắt, Bộ Giáo dục và Đào tạo cần đổi mới phương thức đào tạo, lồng ghép nội dung đào tạo về kỹ năng mềm vào các chương trình giảng dạy, trong đó bao gồm cả chương trình giảng dạy ở bậc phổ thông. Nhà trường cần giúp học sinh hiểu về các loại kỹ năng khác nhau và những kỹ năng cần có để thành công. Cải cách chương trình giáo dục phổ thông ở Việt Nam có thể tham khảo mô hình dựa vào kết quả đầu ra. Chương trình tiếp cận theo hướng nhằm giúp học sinh vận dụng những kiến thức đã học để giải quyết các tình huống do thực tiễn cuộc sống đặt ra. Khác với chương trình truyền thống (theo hướng tiếp cận nội dung) chủ yếu yêu cầu học sinh trả lời câu hỏi "Biết cái gì?" thì chương trình tiếp cận theo năng lực luôn đặt ra câu hỏi: "Biết làm gì từ những điều đã biết?". Các trường nên dành thêm thời gian bồi dưỡng kỹ năng mềm cho học sinh. Chẳng hạn, nhà trường cần quan tâm nhiều hơn đến nhu cầu hoạt động tập thể của học sinh thông qua duy trì các câu lạc bộ của học sinh để trao đổi các vấn đề gia đình, xã hội; tổ chức nhiều và thường xuyên hơn các hoạt động ngoại khóa cho học sinh nhằm nâng cao hiệu quả giáo dục kỹ năng mềm. Bên cạnh đó, nhà trường cần có chủ trương và chính sách hỗ trợ giáo viên đổi mới phương pháp giảng dạy, lồng ghép kỹ năng mềm vào các bài giảng chuyên môn, tăng cường hình thức làm bài tập lớn theo nhóm, thuyết trình, các buổi thảo luận cho học sinh.

Thực tế hiện nay nhiều trường $\mathrm{ÐH}, \mathrm{CĐ}$, thậm chí là $\mathrm{TCCN}$ trên địa bàn TP.HCM đã đưa kỹ năng mềm vào giảng dạy như một chương trình chính khóa. Cụ thể, các trường đã thành lập hẳn một bộ phận chịu trách nhiệm xây dựng kế hoạch, nội dung chương trình và cụ thể hóa chương trình đào tạo huấn luyện kỹ năng mềm; đồng thời đưa vào chương trình đào tạo của trường như những môn học chính khóa khác. Tuy nhiên, công việc đào tạo kỹ năng mềm tại các trường chỉ mang tính hình thức, nặng về lý thuyết chưa mang tính thực tế cao. Nhưng thực tế sinh viên mới ra trường chưa quen với xã hội công nghiệp, làm việc còn rời rạc, thiếu tính kỷ luật, tác phong công nghiệp yếu nên doanh nghiệp không hài lòng. Do đó cần phát triển đào tạo kỹ năng mềm cho sinh viên theo nhiều khía cạnh như sau: 
Thứ nhất: Phát triển kỹ năng mềm dụa trên các chuoong trình hỗ trọ:: Kỹ năng mềm cũng có thể được phát triển một cách gián tiếp thông qua các chương trình hỗ trợ như các hoạt động không nằm trong chương trình chính thức. Các hoạt động này tuy không chính thức, nhưng gián tiếp hỗ trợ các sinh viên trong việc phát triển nhân cách của họ. Những chương trình này cho phép sinh viên khám phá sở thích của họ mà có thể được bồi dưỡng bằng cách đăng ký chúng trong các chương trình ngoại khóa và các hoạt động ngoại khóa đó phản ánh sở thích của họ. Phát triển kỹ năng mềm dựa trên các hoạt động chính thức và không chính thức ở cấp độ Khoa. Các Khoa cũng có thể đóng một vai trò quan trọng trong việc nâng cao kĩ năng mềm giữa các sinh viên với các hoạt động chính thức như tổ chức các cuộc hội thảo, hội nghị.

Thứ hai: Phát triển Kỹ năng mềm dựa trên dạy và học chính khóa. Phát triển kỹ năng mềm bằng cách tích hợp nó trong các khóa học hiện có. Đây có lẽ là một cách thiết thực nhất trong việc khắc ghi kỹ năng mềm cho sinh viên, trong khi hầu như không cần thay đổi hoặc thay đổi rất ít cấu trúc khóa học hiện tại. Trong mô hình này, sinh viên phát triển kỹ năng mềm trong suốt toàn bộ thời gian khóa học của họ, có thể chỉ là một số kỹ năng nếu không phải tất cả các kỹ năng được tích hợp trong những môn học được dạy. Tuy nhiên, nhiệm vụ của các Khoa là xác định những môn học nào có thể được gắn vào với nhiều hoặc ít các yếu tố kỹ năng mềm. Như vậy, các giáo viên nên được tham gia sâu vào các khía cạnh thực hiện, trong khi sinh viên cần được thông báo về những khía cạnh gì họ sẽ được đánh giá và đánh giá như thế nào. Vì giảng viên đóng vai trò quan trọng trong việc thực hiện và đánh giá các khía cạnh, các giảng viên phải sáng tạo trong việc thiết kế các module giảng dạy của mình để kết hợp các kỹ năng liên quan. Phong cách giảng dạy nên lấy sinh viên làm trung tâm, nơi sinh viên sẽ tham gia tích cực vào quá trình học tập, trong khi giáo viên đảm nhiệm vai trò như một người trợ giúp. Dạy học dựa trên vấn đề (Problem-based learning), nghiên cứu trường hợp (case study), và những kỹ thuật giảng dạy và học tập khác như các bài trình bày và làm việc nhóm nên được sử dụng rộng rãi thay cho phương pháp giảng dạy và học tập truyền thống. Tuy nhiên, chỉ ngoại trừ các giáo viên từ Khoa Giáo dục là những người đang liên tục tiếp cận với những kỹ thuật giảng dạy và học tập mới, còn những giáo viên từ các Khoa khác có hạn chế về đào tạo và kiến thức về các khía cạnh này. Như vậy 
các giảng viên từ các Khoa khác cần được đào tạo liên tục về kỹ thuật giảng dạy để được trang bị và tăng cường những kỹ năng giảng dạy phù hợp

Thứ ba: Khóa học hoàn thiện kỹ năng mềm cho sinh viên. Trước khi kết thúc học kỳ, mỗi bộ môn trong Khoa nên xác định xem những sinh viên nào còn thiếu kỹ năng mềm để đăng ký một khóa học chính thức "hoàn thiện kĩ năng mềm trong trường học" được cung cấp bởi Khoa. Khóa học kỹ năng mềm có thể được thực hiện bởi các giảng viên chuyên nghiệp hoặc các giảng viên được đào tạo. Để xây dựng chuẩn đầu ra cho sinh viên, ngoài phát huy nội lực bằng việc trang bị những kiến thức chuyên ngành thì trong quá trình giảng dạy, chúng ta nên phối hợp với các công ty chuyên về đào tạo tổ chức những chương trình hỗ trợ thêm về kỹ năng mềm cho sinh viên.

Điều quan trọng là các trường cần phối hợp với các doanh nghiệp trong và ngoài nước xây dựng chương trình huấn luyện kỹ năng mềm. Ở từng ngành sẽ có những tiết huấn luyện, giao lưu với các chuyên gia để họ chia sẽ những kinh nghiệm cũng như môi trường làm việc cho sinh viên tiếp nhận. Hoặc chọn một địa chỉ liên kết chuyên đào tạo kỹ năng mềm cho sinh viên làm hành trang cho sinh viên khi ra trường tự tin hòa nhập với môi trường doanh nghiệp.

\section{Đối với doanh nghiệp}

Hiện nay, hầu hết các doanh nghiệp bắt đầu có bộ phần đào tạo. Hoạt động của bộ phận đào tạo chủ yếu huấn luyện nhân viên mới những qui định và môi trường làm việc của công ty để nhân viên có thể hòa nhập làm quen với mô trường mới. Tuy nhiên, với nhân viên đang làm việc thì hoạt động đào tạo chưa được thực hiện một cách chuyên nghiệp; do đó doanh nghiệp cần tổ chức các khóa đào tạo tập trung. Doanh nghiệp có thể tổ chức các chương trình đào tạo tập trung thông qua các địa chỉ đào tạo chuyên nghiệp. Hình thức đào tạo này đem đến cho doanh nghiệp một đội ngũ giảng viên có trình độ chuyên môn trong công tác giảng dạy. Bên cạnh đó, các nhân viên được đào tạo tập trung với chất lượng tương đối đồng đều, có thể hình thành các chuẩn mực trong quy trình làm việc. Các khóa đào tạo 
sẽ giúp nhân viên làm việc nhất quán, tập trung; tăng cường tinh thần làm việc với đội nhóm

Để đạt được điều đó, doanh nghiệp phải chọn cho mình một địa chỉ đào tạo đáng tin cậy dựa trên các tiêu chí: chương trình học, danh sách giảng viên, lĩnh vực chuyên môn, danh sách khách hàng của dịch vụ, ý kiến phản hồi từ các khách hàng. Việc chọn dịch vụ đào tạo không nên dựa trên mức học phí thấp; cần tránh các chương trình học nặng tính hàn lâm; giảng viên có trình độ học thuật cao nhưng thiếu kinh nghiệm làm việc, không nắm bắt các vấn đề thời sự...

Đối tượng đào tạo phải là những người biết chủ động tìm kiếm các cơ hội học hỏi, biết đặt ra mục tiêu cá nhân và có thái độ tích cực để việc học đạt kết quả trọn vẹn. Mặt khác, lãnh đạo phải luôn thể hiện quan điểm của mình về tầm quan trọng của việc đào tạo đối với nhân viên và cam kết những chính sách hỗ trợ cho công tác đào tạo để nhân viên nỗ lực hết mình.

Nội dung đào tạo phải được lựa chọn để nâng cao năng lực chuyên môn của nhân viên và đáp ứng mục tiêu phát triển của doanh nghiệp chứ không phải theo xu thế của xã hội hay nhu cầu cá nhân. Mặt khác, cần tạo cơ hội lựa chọn cho nhân viên bằng cách lắng nghe ý kiến phản hồi của nhân viên để biết được ưu - nhược điểm của chương trình đào tạo: Liệu nó đã thực sự phù hợp chưa, nhân viên thích được đào tạo ở lĩnh vực nào?

Sau một thời gian thực hiện chế độ đào tạo, phải luôn tổ chức đánh giá kết quả đào tạo và việc chuyển giao kết quả đó vào thực hiện công việc. Từ đó, lãnh đạo doanh nghiệp sẽ có cơ sở để khuyến khích duy trì công tác đào tạo hay tìm hướng đi khác phù hợp hơn. Đây cũng là một dịp để đánh giá khả năng học hỏi và tiến bộ của cấp dưới.

\section{Tài liệu tham khảo}

CIMO [Viện nghiên cứu quản lý kinh tế Trung Ương], 2015. Năng suất lao động Việt Nam 2015. Truy cập lần cuối ngày 26 tháng 06 năm 2016, từ < http://www.ciem.org.vn/tabid/77/articletype/ArticleView/articleId/1532/default.aspx > 
Giao, H. N. K. (1996a). Hướng dẫn tóm tắt Chiến luợc Công ty. Thành phố Hồ Chí Minh: Nhà Xuất bản Thống kê.

Giao, H. N. K. (1996b). Quản trị Tiếp thị Toàn cầu. Thành phố Hồ Chí Minh: Nhà Xuất bản Thống kê.

Giao, H. N. K. (2004a). Diễn thuyết truớc Công chúng-Làm sao để thu hút Khán giả? Thành phố Hồ Chí Minh: Nhà Xuất bản Thống kê.

Giao, H. N. K. (2004b). Kỹ năng làm việc-Skills for Success (S4S) (Vol. 2): Nhà Xuất bản Thống kê.

Giao, H. N. K. (2004c). Kỹ năng làm việc-Skills for Success (S4S) (Vol. 1). Thành phố Hồ Chí Minh: Nhà Xuất bản Thống kê.

Giao, H. N. K. (2004d). Kỹ năng Thuoong lương- 7 bước RESPECT. Thành phố Hồ Chí Minh: Nhà Xuất bản Thống kê.

Giao, H. N. K. (2004e). Marketing Công nghiệp- Phục vu Khách hàng là các Tổ chức. Thành phố Hồ Chí Minh: Nhà Xuất bản Thống kê.

Giao, H. N. K. (2004f). Marketing Dịch vu- Mô hình 5 Khoảng cách Chất luợng Dịch vu. Thành phố Hồ Chí Minh: Nhà Xuất bản Thống kê.

Giao, H. N. K. (2004g). Marketing Dịch vu- Phục vu Khách hàng tốt hơn. Thành phố Hồ Chí Minh: Nhà Xuất bản Thống kê.

Giao, H. N. K. (2004h). Quan hệ Công chúng- Để người khác gọi ta là PR. Thành phố Hồ Chí Minh: Nhà Xuất bản Thống kê.

Giao, H. N. K. (2004i). Quản trị Bán hàng- Đội ngũ Bán hàng tốt chua? . Thành phố Hồ Chí Minh: Nhà Xuất bản Thống kê.

Giao, H. N. K. (2004j). Quản trị Chiến lược Công ty-Phát huy Tiềm lục Cạnh tranh (Vol. 2). Thành phố Hồ Chí Minh: Nhà Xuất bản Thống kê.

Giao, H. N. K. (2004k). Quản trị Chiến lược Công ty- Phát huy Tiềm lục Cạnh tranh (Vol. 1). Thành phố Hồ Chí Minh: Nhà Xuất bản Thống kê.

Giao, H. N. K. (20041). Quản trị Công ty Đa quốc gia- Quản lý tù sụ đa dạng Văn hóa (Vol. 1). Thành phố Hồ Chí Minh: Nhà Xuất bản Thống kê. 
Giao, H. N. K. (2004m). Quản trị Công ty Đa quốc gia- Quản lý tù sụ đa dạng Văn hóa (Vol. 2). Thành phố Hồ Chí Minh: Nhà Xuất bản Thống kê.

Giao, H. N. K. (2004n). Quản trị học- Để Quản lý không còn là quá khó (Vol. 2). Thành phố Hồ Chí Minh: Nhà Xuất bản Thống kê.

Giao, H. N. K. (2004o). Quản trị học- Để Quản lý không còn là quá khó (Vol. 1). Thành phố Hồ Chí Minh: Nhà Xuất bản Thống kê.

Giao, H. N. K. (2004p). Quản trị Marketing-Marketing để Chiến thắng. Thành phố Hồ Chí Minh: Nhà Xuất bản Thống kê.

Giao, H. N. K. (2010). Mạn đàm thước đo Văn hóa Doanh nghiệp trong các Ngân hàng thương mại. Tạp chí Ngân hàng, Ngân hàng Nhà nuớc VN, 22, 25-27. doi:10.31219/osf.io/rtqz4

Giao, H. N. K. (2011). Giáo trình Marketing Du lịch. Thành phố Hồ Chí Minh: Nhà xuất bản Tổng hợp

Giao, H. N. K. (2012a). Giáo trình Cao học Quản trị Kinh doanh Quốc tế. Thành phố Hồ Chí Minh: Nhà xuất bản Tổng hợp.

Giao, H. N. K. (2012b, 16/06/2012). Học chiến luọcc tù̀ doanh nghiệp siêu nhỏ- Tại sao không? Paper presented at the Hỗ trợ Doanh nghiệp nhỏ và vừa vượt qua khủng hoảng, Trường Đại học Tôn Đức Thắng.

Giao, H. N. K. (2012c). Về việc xếp hạng các trường đại học Việt Nam. Tạp chí Nghiên cứu Tài chính-Marketing, 7-8, 77-80. doi:10.31219/osf.io/6yqem

Giao, H. N. K. (2014a). Báo cáo về đào tạo Sau Đại học. Paper presented at the Giải pháp nâng cao chất lượng đào tạo sau đại học, Trường Đại học Tài chính- Marketing.

Giao, H. N. K. (2014b). Đào tạo sau đại học-Tầm nhìn và nhũng việc cần làm. Paper presented at the 10 năm đào tạo đại học 2004-2014, Trường Đại học Tài chính Marketing.

Giao, H. N. K. (2014c, 15/07/2014). Nanyang Business School- Mô hình đào tạo quốc tế đáng nghiên cứu. Paper presented at the Chương trình đào tạo quốc tế trong bối cảnh hội nhập, Trường Đại học Tài chính- Marketing. 
Giao, H. N. K. (2014d, 28/10/2014). Thu viện sau đại học- Nhũng việc cần làm ngay. Paper presented at the Nâng cao hiệu quả hoạt động thư viện, Trường Đại học Tài chính Marketing.

Giao, H. N. K., \& Bình, N. V. (2011). Giáo trình Nghiệp vu Nhà hàng. Thành phố Hồ Chí Minh: Nhà xuất bản Tổng hợp.

Giao, H. N. K., \& Bình, N. V. (2014). Giáo trình Nghiệp vu Nhà hàng. Hà Nội: Nhà Xuất bản Thống kê.

Giao, H. N. K., Bình, N. V., \& Tùng, N. S. ( 2014). Giáo trình Quản trị Kinh doanh Khách sạn. Hà Nội: Nhà Xuất bản Thống kê.

Giao, H. N. K., \& Hải, T. H. (2016). Vận dụng BSC trong đánh giá quản trị chiến lược tại Công ty Điện lực Tân Thuận. Tạp chí Công Thuơng- Bộ Công thuơng, 4, 73-80. doi:10.31219/osf.io/5a6gc

Giao, H. N. K., Hoan, N. C., Dũng, T. Q., Vinh, N. L., \& Anh, L. T. L. (2014). Giáo trình Quản trị Kinh doanh Lũ hành. Hà Nội: Nhà Xuất bản Thống kê.

Giao, H. N. K., \& Hương, Đ. T. (2010). Các nhân tố tác động đến định hướng khách hàng của nhân viên phục vụ khách sạn TPHCM. Tạp chí Nghiên cứu Tài chính-Marketing, 1, 24-34. doi:10.31219/osf.io/n6mxu

Giao, H. N. K., \& Lộc, N. Q. (2016). Ảnh hưởng của áp lực công việc và động lực làm việc đến hiệu quả công việc của nhân viên tại khách sạn Quê Hương Liberty. Tạp chí $D u$ lịch Việt Nam, Tổng Cục Du lịch, 1-3. doi:10.31219/osf.io/szw37

Giao, H. N. K., \& Minh, H. V. (2016). Các yếu tố ảnh hưởng đến động lực làm việc của công nhân tại công ty Điện lực Tân Thuận. Tạp chí Công Thương- Bộ Công thưong, 10, 142-147. doi:10.31219/osf.io/z94v8

Giao, H. N. K., \& Phong, N. L. D. (2015). Ảnh hưởng của công bằng trong tổ chức đến sự hài lòng đối với công việc của nhân viên tại trường Đại học Tài chính - Marketing. Tạp chí Nghiên cứu Tài chính- Marketing, 29, 30-36. doi:10.31219/osf.io/mgd3r

Giao, H. N. K., \& Phương, V. T. M. (2011). Đo lường sự thỏa mãn công việc của nhân viên sản xuất tại công ty TNHH TM Tân Hiệp Phát. Tạp chí Phát triển Kinh tế, 6, 15-21. doi:10.31219/osf.io/uwcae 
Giao, H. N. K., \& Sơn, L. T. (2014). Giáo trình Quản trị Chiến lược cho tổ chúc Du lịch. Hà Nội: Nhà Xuất bản Thống kê.

Giao, H. N. K., \& Tài, L. T. T. (2016). Các nhân tố tác động đến gắn kết của nhân viên với tổ chức tại UFM. Tạp chí Nghiên cưu Tài chính- Marketing, 34, 61-67. doi:10.31219/osf.io/9pm2v

Giao, H. N. K., \& Tiên, N. T. (2016). Sự hài lòng của sinh viên đối với chất lượng dịch vụ đào tạo hệ Vừa làm vừa học tại UFM. Tạp chí Nghiên cưu Tài chính-Marketing, 32, 61-67. doi:10.31219/osf.io/2nkxr

Giao, H. N. K., \& Trinh, H. T. (2014). Thống kê mô tả các yếu tố tác động đến sụ hài lòng về chất luợng đào tạo cao học UFM. Paper presented at the Giải pháp nâng cao chất lượng đào tạo sau đại học, Trường Đại học Tài chính- Marketing.

Giao, H. N. K., \& Trường, P. Q. (2015, 06/01/2015). Mối quan hệ giũa sụ hài lòng và truyền miệng tại các trung tâm Anh ngũ ở TPHCM. Paper presented at the Hành vi tiêu dùng mới trong cộng đồng ASEAN: Cơ hội và Thách thức, Trường Đại học Kinh tế- Luật, Đại học Quốc gia TPHCM.

Giao, H. N. K., \& Vinh, N. H. (2015). Các yếu tố ảnh hưởng đến sự sáng tạo trong công việc của nhân viên UFM. Tạp chí Nghiên cứu Tài chính- Marketing, 31, 80-90. doi:10.31219/osf.io/kzavp

Giao, H. N. K., \& Vương, B. N. (2016). Ảnh hưởng của các yếu tố văn hóa doanh nghiệp đến sự gắn bó của nhân viên với tổ chức tại Công ty CP CMC Telecom TPHCM. Tạp chí Kinh tế- Kỹ thuật Bình Duoong, 13, 87-101. doi:10.31219/osf.io/qje82

ILO [Tổ chức lao động thế giới], 2014. Survery Of ASEAN employers of skills and competitiveness. Emerging Markets Consulting. ILO - Asia - Pacific Working Paper Series. Truy cập lần cuối ngày 26 tháng 06 năm 2016, từ <http://www.ilo.org/wcmsp/group/public/asia/ro-bangkok/sro-...2868.pdf>.

VNIES [Viện khoa học giáo dục Việt Nam], 2015. Sinh viên và kỹ năng mềm trong thời kỳ hội nhập. Truy cập lần cuối ngày 26 tháng 06 năm 2016, từ http://vnies.edu.vn/detailnews-view-1-24-1391_sinh-vien-va-ky-nang-mem-trong-thoi-ky-hoi-nhap.html. 
Trung tâm Dự báo nhu cầu nhân lực và Thông tin thị trường lao động TP. Hồ Chí Minh, 2014. Người lao động cần trang bị kỹ năng mềm. Truy cập lần cuối ngày 26 tháng 06 năm 2016, từ < http://www.dubaonhanluchcmc.gov.vn/tin-tuc/3509.nguoi-lao-dongcan-trang-bi-ky-nang-mem.html>. 